DOI: http://dx.doi.org/10.18309/anp.v1i49.1299

\title{
CONCEITOS DE LETRAMENTO E A FORMAÇÃO DE PROFESSORES DE LÍNGUAS
}

\section{CONCEPTIONS OF LITERACY AND LANGUAGE TEACHER EDUCATION}

\author{
Pedro de Moraes Garcez \\ Universidade Federal do Rio Grande do Sul, Porto Alegre, Rio Grande do Sul, Brasil
}

Resumo: Que relevância ou utilidade tem o conceito de letramento no que tange à formação de educadores (da linguagem)? Partindo de uma definição de letramento de larga circulação entre nós, discuto dificuldades para o emprego consistente do termo. Propondo cautela ao relacionar letramento diretamente com aprendizagem, destaco a necessidade de reflexão sobre as concepções de ação pelo uso da linguagem coerentes com tomar o conceito de letramento como relevante e útil com vistas à educação linguística escolar. Para articular isso com educação linguística e formação de professores, apresento minhas convicções acerca do propósito da educação linguística escolar e do lugar da reflexão metalinguística no ensino de línguas. Alertando para uma compreensão equivocada de que os gêneros textuais/discursivos seriam, eles próprios, objetos de ensino, reitero a convicção de que, tendo o letramento como pronto de referência, "uma abordagem funcional e estruturante" (SIMÕES; FILIPOUSKI; MARCHI, 2009, p. 49) dos gêneros permite uma arquitetura didático-pedagógica para a educação linguística escolar. Por fim, referindo propostas coletivas de organização curricular para a educação linguística escolar pautadas pela noção de letramento, argumento que iniciativas de formação devem fomentar o protagonismo de professores-autores-formadores com vistas a uma educação linguística escolar satisfatória frente às demandas e contradições da contemporaneidade.

Palavras-Chave: Ação; Educação Linguística; Letramento; Literacia; Formação de Professores

\begin{abstract}
What relevance or usefulness does the concept of letramento (literacy) have for (language) teacher education? Starting from a definition of wide currency amongst us, I discuss difficulties for the consistent use of the term letramento. Proposing caution when relating it directly with learning, I emphasize the need to reflect about conceptions not only of language but also of action in language use that cohere with the concept. To articulate this with language teacher education, I formulate what I understand to be the purpose of formal language education and the place of metalinguistic reflection in literacy-based language teaching. Alerting to the common misconception that discourse/text genres would thus be seen as objects of teaching in and of themselves, I stress that, with literacy as a reference point, "a functional and structuring approach" (SIMÕES, FILIPOUSKI; MARCHI, 2009) to genres provides adequate pedagogical frameworks for school-based language education. Finally, referring to collective proposals of curricular organization for language education guided by the notion of literacy/letramento, I argue that teacher education initiatives should have as their protagonists those teachers who are themselves authors and teacher educators if we are to foster satisfactory school language education according to the demands and contradictions of our times.
\end{abstract}

Keywords: Action; Language Education; Language Use; Literacy; Teacher Education 


\section{CONSIDERAÇÕES INICIAIS DE ENQUADRE}

O conceito de letramento tem relevância ou utilidade? É da perspectiva de reflexão e atuação como formador de educadores da linguagem que articulo resposta à interrogação feita aos participantes dos Seminários sobre Letramento e Transdisciplinaridade convocados por Inês Signorini e Raquel Fiad (ver apresentação deste número).

\section{LETRAMENTOS, APRENDIZAGENS, REPERTÓRIOS, LÍNGUA/LINGUAGEM E AÇÃO}

\section{Uma definição de letramento boa o suficiente para a formação inicial de professores (de línguas)}

Boa parte da reflexão que sustenta o que formulo aqui tem sido praticada com estudantes de graduação na disciplina de "Linguística e Ensino", a meu encargo desde 2001 no curso de Licenciatura em Letras da UFRGS. Outra vem sendo construída pela interlocução com colegas educadores em encontros de formação continuada de professores (GARCEZ, 2013). Nessas atividades, costumo me pautar pela definição de letramento difundida por Kleiman (1995, p. 19): "conjunto de práticas sociais que usam a escrita, enquanto tecnologia e enquanto sistema simbólico, em contextos específicos, para objetivos específicos".

$\mathrm{Na}$ apresentação que faço do texto de Kleiman (1995) para os estudantes de terceiro ano de Letras, que me relatam encontrar o conceito pela primeira vez na disciplina que ministro, costumo destacar a necessidade de paráfrase dos segmentos práticas sociais (coisas que as pessoas fazem em conjunto) e escrita ("tudo o que se pode ler", na formulação de uma estudante da edição de 2017). Propondo um deslocamento imaginário - ao passado remoto, ou ao convívio com comunidades humanas isoladas - para contemplar a vida sem escrita, busco situar concretamente os entendimentos de tecnologia e sistema simbólico. Para isso recorro à noção de valor monetário como construção histórica calcada em práticas que dependem de registros escritos. Por fim, reitero o caráter sempre situado dessas práticas em contextos de interlocução, convidando para um exercício de observação da rotina pessoal a fim de flagrar eventos de letramento na vida de cada um. Buscando compor um pequeno rol de exemplos a partir disso, remeto os estudantes para a definição, mais adiante no texto de Kleiman, de "evento de letramento" como unidade de observação dos fenômenos constituintes do letramento - tal como afirmam Barton e Hamilton (2012 [1998]), Brandt e Clinton (2002), Lillis e McKinney (2013) e Street (2011) - as práticas sociais que usam a escrita, enquanto tecnologia e sistema simbólico, em contextos específicos, para objetivos específicos.

\section{Entender letramento como "ato ou efeito de letrar ou ser letrado" e equacionar letramento com aprendizagem podem reduzir o escopo dos fenômenos e a relevância do conceito}

Entre tantas definições adequadas, a que discuti acima expõe em dicção clara os elementos principais para referência ao universo de fenômenos do letramento. Para as discussões sobre letramento e transdisciplinaridade, a definição me parece novamente bemapanhada, em particular por referir ao conjunto das incontáveis práticas sociais em que as

\footnotetext{
${ }^{1}$ Na definição de Heath (1982, p. 50), base para a discussão de Kleiman (1995): "ocasiões em que a linguagem escrita faz parte da natureza das interações dos participantes e dos processos e estratégias interpretativos deles" (occasions in which written language is integral to the nature of participants' interactions and their interpretive processes and strategies) (tradução nossa).
} 
pessoas de algum modo usam a escrita para fazer seja lá o que for que estiverem fazendo juntas.

Quero destacar nessa definição a ausência de elementos relativos a algo muito caro a nós educadores: a aprendizagem. Com isso não nego que possa haver transformações nas pessoas quando participam de eventos de letramento, nem afirmo que elas não aprendam quando se engajam em práticas de letramento. Quero, isto sim, apontar que o conjunto de práticas de letramento não se limita àquelas que produzem transformações ou aprendizagem² ${ }^{2}$.

Com efeito, entendo que o termo "letramento", que cunhamos no Brasil, tem uma composição morfológica insidiosa. O sufixo "-mento" conspira fortemente com as nossas expectativas de educadores para que o conceito seja tomado, em viés pedagógico, como "ato ou efeito de letrar ou ser letrado", o que me parece também distinto do conjunto das práticas sociais que usam a escrita, enquanto tecnologia e enquanto sistema simbólico, em contextos específicos, para objetivos específicos. Daí surgem metáforas como "travessia" e "transformação", deslizando para aprendizagem.

Essa conflação não é, em si, de todo infeliz. Todavia, creio que um entendimento de letramento como ato ou efeito de letrar ou ser letrado reduz o escopo de fenômenos abrangidos no imenso conjunto de práticas sociais do letramento, levando ao apagamento de aspectos importantes e exacerbação de outros, gerando inclusive certas "confusões", de que alguns se valem para questionar a validade e a relevância do conceito. Em particular para a discussão de sua utilidade como conceito "funcional e estruturante" para a arquitetura didático-pedagógica na educação linguística escolar, sobre o que tratarei na segunda parte deste ensaio, equacionar letramento e processo de aprendizagem me parece produzir um curto-circuito que tornaria o próprio conceito vago, redundante e, assim, dispensável, inútil ${ }^{3}$.

Ao emparelhar letramento com metas pedagógicas, perde-se precisão em ao menos três aspectos. Um diz respeito ao fato de que, quando se envolvem em práticas de letramento, as pessoas não necessariamente estão engajadas no trabalho de aprender ou de ensinar. Tratar essas práticas como aprendizagem diminui a atenção às atividades em curso nas esferas em que as pessoas se encontram, apagando o evento letramento como ponto de referência observável de como as pessoas fazem certas coisas (umas com as outras, mediadas pela escrita...). Entre outros corolários disso, perde-se de vista também, por exemplo, que o conjunto das práticas sociais do letramento é bem mais amplo do que as que devem ser prioritárias para a educação escolar. Dada ainda a tendência de, como educadores, limitarmos o escopo de "aprendizagem" ao que é recomendável e positivo - "quem lê aprende" (só coisas boas), apagam-se os diversos objetos de aprendizagem que não são defensáveis como objetos de ensino, mas que podem ser aprendidos em práticas de letramento. Corre-se assim outra vez o risco de tomar o universo da escrita como divisor de águas entre dois tipos de pessoas e sociedades, reiterando assim o equívoco da noção, amplamente rejeitada contemporaneamente nos estudos do letramento (BRANDT; CLINTON, 2002, p. 337-338; STREET, 2011, p. 58; LILLIS; MCKINNEY, 2013, p. 416), de um "great divide" entre oralidade e letramento, valorando o segundo para sugerir que o domínio da escrita produziria alterações únicas nas culturas e nas capacidades cognitivas humanas.

\footnotetext{
${ }^{2}$ Para síntese de reflexão sistemática sobre as noções de participar/participação e aprender/aprendizagem na interação social em cenários de produção de conhecimento, ver Garcez, Frank e Kanitz (2012).

${ }^{3}$ Isso também vale para a sobreposição entre letramento e leitura, que fica evidente quando solicito aos estudantes a quem apresento o conceito de letramento que detectem eventos de letramento em suas rotinas, e muitos listam atos individuais de leitura. Se letramento e leitura fossem sinônimos, não haveria fenômenos distintos, nem necessidade de cunhar um termo para referir ao letramento.
} 


\section{Afinal, de que vale o conceito de letramento?}

Para a educação linguística escolar, e em especial para propostas curriculares e político-pedagógicas cidadãs, tomar como ponto de referência o conjunto de práticas sociais que o letramento encerra importa não apenas para se ter clareza de que o escopo do ensino de línguas vai além do conjunto de formas linguísticas normatizadas, mas, principalmente, para se ter uma base empírica observável do que são essas práticas e de como se configuram. Com esses pontos de referência das práticas sociais, pode-se então tomar decisões políticopedagógicas sobre quais delas devem compor currículos (e em que progressão), quais devem ser objeto de atenção para a emulação pelos estudantes (e quais não), que capacidades devem ser aprendidas para tanto (metas de aprendizagem), que recursos expressivos ${ }^{4}$ precisam ser ensinados (objetivos de ensino) (ver SIMÕES; MARCHI; FILIPOUSKI, 2009; SIMÕES et al., 2012; SCHLATTER, 2009; SCHLATTER; GARCEZ, 2009, 2012). Ou seja, o conceito de letramento permite examinar, na experiência vivida das coletividades, o que é feito em mediação que envolve a escrita, e a atenção a isso permite eleger o que cabe à escola cultivar e desenvolver, e aí sim (na educação escolar que se pauta pelo conceito) tomar decisões sobre o que ensinar e aprender.

\section{Concepções de linguagem compatíveis com o conceito de letramento}

Talvez seja mais feliz o termo cunhado em português europeu, "literacia", para o que passamos a nomear como letramento. Por outro lado, sendo duvidosa a possibilidade de rever a cunhagem, não é de todo infeliz, como já apontei, aproximar letramento e alfabetização, nem evocar transformação, dado que a mediação da escrita para convívio com os outros parece produzir transformação não só no nosso repertório de práticas para a participação, mas também no acesso ao conhecimento (BRITTO, 2007) e, crucialmente para os educadores da linguagem, ao repertório linguístico valorizado. Nisso, reconheça-se que, se por um lado há muito que não é linguístico nas mediações semióticas que se fazem relevantes para os participantes de eventos de letramento, por outro, a maior parte dos textos nesse universo em especial os que interessam à educação escolar - são vasados em linguagem verbal escrita, às vezes única e exclusivamente nela, os ditos textos eruditos (talvez mais bem nomeados como "de interlocução pública formal"). Seja como for, para a adoção de letramento como noção relevante e útil, importa ter em conta concepções compatíveis de língua e de linguagem.

No quadro das ideologias de linguagem, em que as teorias linguísticas acadêmicas figuram em meio a tantas outras "ideias mediante as quais participantes e observadores enquadram seus entendimentos acerca das variedades linguísticas e depois mapeiam esses entendimentos sobre as pessoas, eventos e atividades que lhes são significativas" (IRVINE; GAL, 2005, p. 35), serão necessariamente amplas as concepções de língua compatíveis com a adoção de uma perspectiva do letramento. Podem estar atentas a formas do(s) código(s) linguístico(s) em que se plasmam os textos escritos e orais de que são feitas as práticas sociais nos eventos de letramento, mas deverão também alargar a atenção para outros signos regularmente explorados na produção de efeitos de sentido, como ilustrações e formas tipográficas, gestos e olhares. Isso já torna difícil a distinção entre língua e linguagem, que o português nos permite (e obriga a) fazer. Tendo em vista que a produção de sentidos é crucial

\footnotetext{
${ }^{4}$ Note-se que "recursos expressivos" deliberadamente excedem recursos estritamente linguísticos, dado que, mesmo nos próprios textos que materializam a escrita e caracterizam qualquer prática de letramento como tal, muitas vezes há recursos constitutivos tipicamente textuais, não linguísticos, como ilustrações, imagens, gráficos, tabelas etc. sobre os quais, aliás, os compêndios de gramática pouco ou nada têm a dizer (ver BRITTO, 2004, p. 132-134).
} 
para as leituras em que se fundam as práticas de letramento, essa (in)distinção será uma preocupação central dos que adotam o letramento como noção relevante e útil. Por isso, mesmo que diversas concepções de língua possam informar a compreensão dos fenômenos do letramento, serão menos imediatamente relevantes as que restringem seu interesse às línguas naturais humanas estritamente como códigos que geram frases e proposições (ver MOITA LOPES, 2013); e mais compatíveis as que veem aí principalmente fenômenos nomeados em torno de termos como "prática social, interação, ação conjunta".

Mais que isso, se tivermos em conta que os estudos do letramento se configuraram como tal numa intersecção de estudos da linguagem que não se circunscreveu à Linguística, é possível que as concepções de língua/linguagem compatíveis com a perspectiva do letramento sejam algo difusas, ainda que - inescapavelmente, me parece - abarquem elementos para além do(s) código(s) linguístico(s). Parece ponto pacífico que o letramento deve receber tratamento analítico necessariamente multi ou transdisciplinar.

\section{Concepções de ação e os "sujeitos" do letramento}

Com efeito, proponho que, para a adoção fundamentada de letramento como conceito relevante e útil, além de concepções de língua/linguagem, é crucial alguma consciência a respeito de concepções de ação, a que os estudiosos da linguagem em Linguística dão escassa atenção, mas que estão no cerne da Sociologia (GIDDENS, 1984; ATKINSON; HERITAGE, 1984) e, mais perto de nós, da Antropologia da Linguagem (DURANTI, 1997). Se o letramento diz respeito ao conjunto de práticas sociais que envolvem a escrita, deve ser evidente que diz respeito a fazer coisas em conjunto, ordenadamente, com outras pessoas. Se eventos de letramento são ocasiões de encontros entre pessoas para fazer coisas umas com as outras com objetivos específicos em contextos específicos, a natureza dessa coordenação não deve ser tomada como trivial, mas como trabalho. Tampouco a situação em que decorre cada evento de letramento deve ser negligenciada (GOFFMAN, 2002 [1964]). Os "sujeitos" do letramento, portanto, são gente que produz não apenas sentido, mas ação conjunta, são participantes das ações, agentes, "contidos em corpos físicos, ocupando espaço em situações sociais simultaneamente limitantes e possibilitadoras, que precisam reflexivamente fazer sentido das ações uns dos outros enquanto agem, sem o benefício de um sistema interpretativo completamente compartilhado entre os interlocutores" (GARCEZ, 2017, p. 436).

Conforme Garfinkel e Sacks (1970, p. 342),

as pessoas, ao se ouvirem falando uma língua natural, de algum modo se ouvem como estando engajadas na produção objetiva e na demonstração objetiva de conhecimento de senso comum sobre atividades cotidianas, enquanto fenômenos observáveis e relatáveis ${ }^{6}$.

Em texto seminal apropriadamente intitulado "Sobre estruturas formais das ações práticas"7, Garfinkel e Sacks afirmam que a indeterminação dos recursos linguísticos torna o domínio da linguagem natural "uma realização ocasionada o tempo todo e sem descanso" (p.

\footnotetext{
5 ... contained in physical bodies, occupying space in simultaneously constraining and enabling social situations, who must reflexively make sense of each others' actions as they act, without the benefit of an interpretive system that is shared completely among interlocutors. (Tradução nossa)

${ }^{6}$ We offer the observation that persons, because of the fact that they are heard to be speaking a natural language, somehow are heard to be engaged in the objective production and objective display of common sense knowledge of everyday activities as observable and reportable phenomena. (Tradução nossa)

${ }^{7}$ On formal structures of practical actions. (Tradução nossa)
} 
$345)^{8}$. Por isso, esses sociólogos tratam o que chamam de "domínio da linguagem natural" como o locus da sociabilidade humana, que é necessariamente indicial, contingente aos contextos específicos em que se encontram os participantes da ação e à concatenação de seus propósitos.

Não cabe aqui esmiuçar essa perspectiva particular de ação pelo uso da linguagem (mas ver HERITAGE, 1984; GIDDENS, 1995; GARCEZ, 2008). Para os nossos propósitos, aponto apenas que adotar o conceito de letramento requer consciência, além de concepções de língua/linguagem, de concepções de ação, em especial da ação mediada pelo uso da linguagem. Isso requer teoria social. Resta inadequado, portanto, circunscrever os fenômenos do letramento ao estudo da linguagem informado apenas por teorias linguísticas.

Continência para evitar impor os dramas epistemológicos dos estudos da linguagem à educação escolar, e a utilidade praxeológica do conceito de letramento para a formação de educadores da linguagem

Antes de tratar de formação de professores (de línguas), quero ressalvar que, a despeito da importância das reflexões acadêmicas que nos ocupam aqui,

\begin{abstract}
Não cabe esperar que os professores façam leituras extensas e minuciosas para compreender e se apropriarem de conceitos e termos, por exemplo - que podem ser caros e preciosos para o desenvolvimento da convicção técnica que se pode esperar dos formadores - para só então estarem aptos a conversar com os doutos sobre questões da ordem do dia da prática educacional escolar. (GARCEZ, 2013, p. 218)
\end{abstract}

A título de síntese, reitero a resposta à indagação sobre a relevância do conceito de letramento: a meu ver, a utilidade do construto está no convite para ter nas práticas sociais o ponto de referência do que as pessoas fazem com a linguagem, especialmente quando a modalidade escrita se faz presente, e, a partir disso, eleger o que cabe cultivar na educação escolar. Dessa visão praxeológica, é possível obter critérios para procedimentos didáticopedagógicos. Um ponto ilustrativo disso diz respeito à quando e por que faz sentido (ou não) propor leitura em voz alta como atividade pedagógica. Essa questão prosaica, do dia a dia das ações pedagógicas, é também agudamente reveladora das posições acerca de propósitos educacionais, metas de aprendizagem e objetivos de ensino. Ter as práticas sociais letradas em vista permite clareza de que, se o propósito é exercitar alguma prática social de letramento, deve-se observar como procedem os que já participam delas, para participar como eles e, se desejável e possível, com eles, ou mesmo contra eles.

\title{
II LETRAMENTOS, ENSINO DE LÍNGUAS E FORMAÇÃO DE PROFESSORES
}

\section{Para que serve ensinar Língua Portuguesa e Literatura?}

Há quem evite responder. Há respostas autoritárias: "Porque é a única língua oficial do País!" No mais das vezes, ouço e leio respostas vagas e imprecisas, ou que seguem invocando "as formas corretas da língua", "o domínio da norma culta da língua", a reflexão sobre "os mais diversos processos que envolvem a língua e a linguagem", a capacitação do aluno para "a comunicação e expressão nos mais diversos contextos..." Curiosamente, é raro encontrar menção a escrita.

\footnotetext{
${ }^{8}$ In sum, the mastery of natural language is throughout and without relief an occasioned accomplishment. (Tradução nossa)
} 
Entendo que esta formulação concisa de Britto (1997, p. 14) expressa conquistas da reflexão acadêmica nos estudos da linguagem nas últimas décadas: "o papel da escola é dar acesso à escrita e aos discursos que se organizam a partir dela". Há aí, claro, muito também a qualificar: trata-se de toda a educação escolar, cabendo ao componente de Língua Portuguesa e Literatura a liderança; escrita diz respeito a toda a extensão do que se pode ler a partir de algum registro; e os discursos que se organizam a partir da escrita podem ser tão ou mais importantes do que ela própria.

\section{Que português ensinar? Ainda cabe essa questão?}

A formulação de Britto (1997) encerra, a meu ver, uma perspectiva de letramento nos termos discutidos na seção anterior ao sustentar que interessa ampliar o repertório de práticas sociais de letramento dos participantes da educação escolar. Na obra de Britto (1997, 2004, 2007), tal como na de autores como Faraco (2006, 2008, 2012), entende-se que, para que essa conquista acadêmica seja também conquista da educação escolar, esse propósito precisa ser discutido em contraste com o propósito hegemônico de dar conhecimento da tradição gramatical - "o modelo pedagógico medieval" de ensino de língua (FARACO, 2006, p. 21) e suas deturpações brasileiras que derivam para a gramatiquice e o normativismo.

Nos tempos de "inflexão normativa" (PAGOTTO, comunicação pessoal) que vimos atravessando nas últimas décadas, creio que a discussão sobre a "língua boa" do Brasil (ou do mercado sociolinguístico que se tenha em vista) segue crucial para a formação de professores, inclusive para que tenham em vista as outras agências de letramento e redes de cooperação (ver SILVA, neste número). Ter como ponto de referência concreto as práticas sociais do letramento importa para isso também. Situar as formas linguísticas encontradas em produções linguísticas e textuais permite vê-las em perspectiva e, quem sabe, examinar as curvas e vias dessa inflexão normativa ainda perturbadora para muitos, daí a sensação de "sombra do caos" a que se referia Britto (1997).

Um exemplo concreto, revelador, é o das ocorrências de "ele/ela/eles/elas" na posição de objeto. Basta percorrer com atenção textos que sustentam práticas sociais de letramento para verificar que essas ocorrências são comuns e produtivas, inclusive em textos literários de autores prestigiosos com grande público leitor, porém muito menos abundante em textos que estão no centro de situações momentosas de debate político público, como, por exemplo, editoriais de jornais, relatórios anuais de empresas, cartas abertas, manuais de ensino de Química ou Medicina, de Geografia ou Sociologia (sem falar em textos legais, jurídicos e oficiais), nos quais são muito produtivos os pronomes "exclusivamente objeto" o/a/os/as (e suas contrações). É preciso atentar para isso ao planejar ensino mirando metas de aprendizagem voltadas para a construção de sentidos em discursos que se organizam a partir da escrita numa sociedade como a nossa, em que se escreve numa língua repleta de formas alternativas, algumas peculiares a apenas uma fração diminuta, mas crucial, de suas realizações escritas.

$\mathrm{Na}$ minha experiência de formação, busco empreender essa discussão por meio da produção de infográficos que resumem reflexões sociolinguísticas (no meu entendimento delas, é claro). Essa discussão - que empreendi com professores brasileiros, africanos (ver SCHLATTER; GARCEZ, 2017a) e uruguaios - só faz sentido pela orientação a um possível propósito de ensino de Língua Portuguesa e Literatura voltado para a expansão do repertório de práticas sociais de letramento, com vistas à ampliação da participação do cidadão em esferas de ação que exigem a compreensão de formas específicas para a participação em certos discursos em certos contextos específicos.

Há muito ainda a ajustar, mas a versão mais recente do infográfico é a seguinte: 
Figura 1: Infográfico Mercado Sociolinguístico Brasil

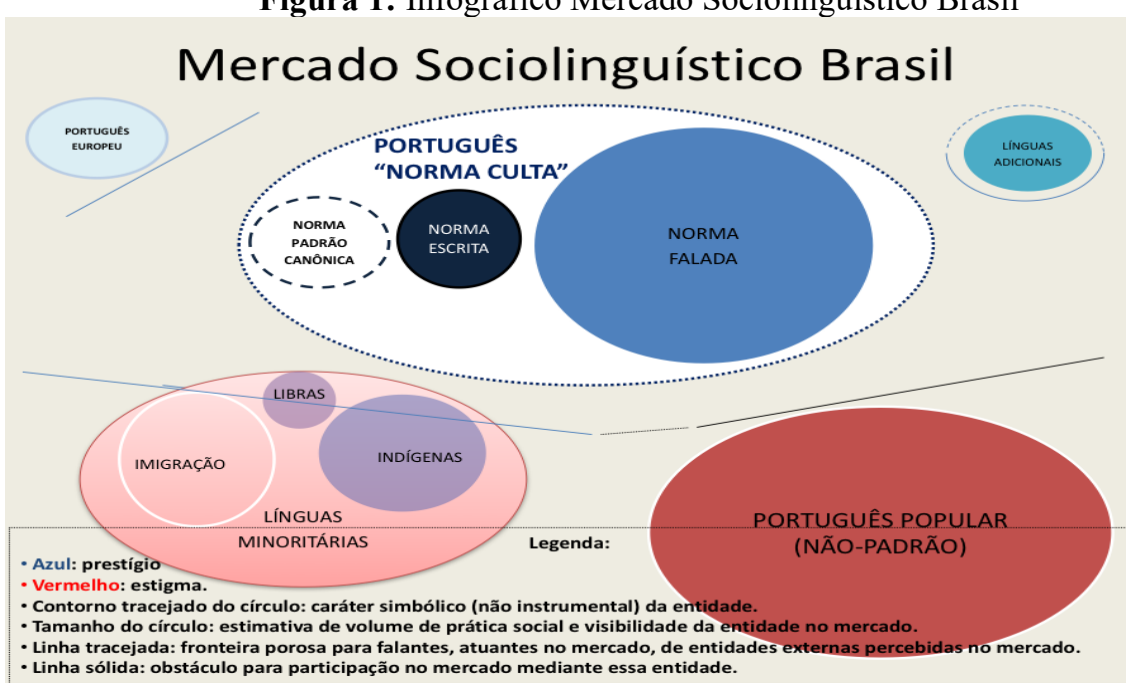

Fonte: O autor

O suporte concreto da representação infográfica permite gestos indiciais que catalisam lampejos na discussão a respeito do propósito de ensino de Língua Portuguesa e Literatura, o objeto de ensino a ser privilegiado e, mais adiante, os eventos e as práticas sociais que podemos ter como pontos e universos de referência. Pergunto, por exemplo, o que é "padrão"? E depois pergunto se frases como "Eu guardei ela grudada na minha pele" estão adequadas a esse "padrão" ou se seriam objeto de "correção" se produzidas nos textos de estudantes. E aí podemos ver uma coleção de ocorrências, inclusive as que aparecem na obra da autora consagrada, membra e ex-presidente da Academia Brasileira de Letras, Ana Maria Machado9 . Podemos então ler obras de Marcelo Carneiro da Cunha e tantos outros autores de literatura infanto-juvenil, e talvez possamos considerar que, para quem quiser "ser um desses textos quando crescer", ele/ela/eles/elas serão os pronomes-objeto de preferência, talvez categoricamente.

Sobre o que está representado no infográfico para os fins da presente discussão, faço aqui apenas dois apontamentos acerca de como o conceito de letramento informa a proposta. O primeiro é que há contato entre as entidades, e variação em todas as entidades representadas, até na norma padrão canônica,

a idealização dos usos linguísticos de uma comunidade oficial, estabelecida no confronto histórico de construção de cultura nacional e funcionando como uma lei, que determina padrões - orais e escritos - e a referência de avaliação e correção das formas linguísticas (BRITTO, 2004, p. 125).

O segundo é que qualificar o acesso à escrita e aos discursos que se organizam a partir dela, ou ampliar o repertório de práticas sociais necessárias para a participação plena do cidadão, não passa por ter como objeto de ensino qualquer das entidades linguísticas representadas, nem a própria norma escrita, entendida aqui como evidente na produção dos escritores cotidianos, que chega ao cidadão em geral apenas na sua condição de leitor - a língua tipográfica (print language), segundo Anderson (1983), aquela que pode arrolar centenas de milhares de vocábulos além dos que o cidadão precisa para a vida cotidiana. Nessa mirada, a aula de Língua Portuguesa e Literatura não tem por objetivo o "domínio" de qualquer das entidades linguísticas representadas no infográfico, embora certos recursos linguísticos que caracterizam algumas possam e devam ser ensinados. A língua boa do

\footnotetext{
${ }^{9}$ A frase reproduzida ocorre em Bisa Bia, bisa Bel.
} 
letramento pode ser qualquer uma que sirva para as práticas sociais relevantes, inclusive para a discussão de textos que se lê para fazer alguma coisa com base no que se leu, muitas vezes em conjunto com outros. Esse "domínio da linguagem natural" pode se dar inclusive por uma "mistura de línguas", o que vem recentemente se chamando de "translinguagem" (GARCÍA; LIN, 2017) e "transidioma" (JAQUEMET, 2016), na extensão promissora que Silva e coautores fazem, "transletramentos" (LOPES et al. 2017). Pode, por outro lado, ser um objeto bem mais regulado, como em geral é o que se exige em certos espaços de exposição ou debate político público.

Por um ângulo, algo mais amplo se vislumbra como ponto de chegada, como metas de aprendizagem, que são as práticas sociais letradas a serem selecionadas para cultivo. Por outro, há algo menos ambicioso do que o domínio da "totalidade da língua" ou mesmo do conjunto das "mais diversas" práticas sociais letradas. Trata-se, isto sim, de expor os estudantes a formas relativamente estáveis de enunciados para a prática de discursos que se organizam a partir da escrita. E esse horizonte menos delimitado, mais variado, requer um entendimento de que muito do que está nas metas de aprendizagem pode estar além do controle e do conhecimento dos educadores e, portanto, será mais produtivamente explorado como objeto de brincadeira (ler, escrever e declamar poemas para falar de temas como amizade e violência no lugar onde se vive e além), ou investigação conjunta (ler e debater reportagens e artigos de opinião para tratar de temas como da memória ou do saneamento básico no lugar onde se vive e além).

Para essa "humildade" epistemológica e pedagógica, é relevante ter em vista a imensidão do conjunto de práticas sociais que usam a escrita, enquanto tecnologia e enquanto sistema simbólico, em tantos contextos específicos, para tantos objetivos específicos. É útil também ter como ponto de referência os modos e formas de organização das pessoas nas práticas sociais, que manifestam certos discursos, que se organizam a partir da escrita em esferas cruciais de participação humana, em especial as que permitem acesso ao conhecimento e ao debate político público. Tendo isso em conta, creio que será também mais evidente o bom sentido educacional de se fomentar o trânsito de experiências em práticas de letramento entre as diversas agências de letramento, reconhecendo que a instituição escolar é apenas uma delas. Estando ela aí, bem que se podia querer que fosse mesmo a principal, sim?

\section{Gênero do discurso como simulacro de letramento}

Nas últimas décadas, um discurso de transposição didática dessa visão de educação linguística escolar, e de Língua Portuguesa e Literatura em particular, tem se consolidado, não sem problemas, em torno do conceito de gênero textual/discursivo (DI FANTI, 2009). Para isso contribui a promessa de "relativa estabilidade" dos enunciados reunidos em cada "tipo", um alento em meio às múltiplas diversidades evidentes no conjunto das práticas do letramento.

Um interlocutor na plateia da sessão pública que fechou a programação do primeiro Seminário Letramento e Transdisciplinaridade organizado por Inês Signorini e Raquel Fiad em maio de 2017 na UNICAMP (ver a apresentação deste número) formulou esse discurso concisamente: "Ensinar gênero textual, fazer sequência didática, inserir no projeto. Essa tríade vai determinar o professor que faz o novo." A síntese encerra passos de uma conquista histórica ainda em curso. Registra que está desalojada, no discurso ao menos, a tradição de ensino de língua centrada em dar conhecimento da tradição gramatical ensimesmada. Há elementos indicativos do que vai no seu lugar e de como planejar o ensino com base nisso: gênero textual, sequência didática, projeto. 
Contudo, pode residir também aí um equívoco disseminado: atrelado a letramento, gênero passa a objeto de ensino. Com efeito, Filipouski, Marchi e Simões (2009) já alertavam o interlocutor-professor:

quanto aos gêneros, enfatiza-se aqui uma abordagem funcional e estruturante. Não se trata de substituir o ensino declarativo de questões gramaticais e períodos literários pelo ensino declarativo de gêneros: o aluno aprende uma definição de uma lista de características de um gênero para depois repetir. Não se está propondo um novo formalismo. (p. 96)

Uma proposta efetiva e coerentemente pautada pelo conceito de letramento deve ter gêneros como eixos funcionais e estruturantes, tanto de unidades didáticas quanto da progressão curricular. Para isso, no entanto, deve-se atentar para temáticas, aspecto sintomaticamente ausente na síntese do interlocutor reproduzida acima. Considerando que as pessoas fazem coisas que exigem a escrita para tratar dos temas que lhes importam, as temáticas devem ser elemento constitutivo da arquitetura de projetos pedagógicos pautados pela perspectiva do letramento. $\mathrm{O}$ apagamento desse elemento pode estar na raiz do problema de didatização dos gêneros como objeto de ensino ensimesmado.

Uma conquista recente dos formadores de professores que se pautam pela noção de letramento é flagrar esse problema, e creio que temos por tarefa rever esse equívoco, começando entre nós mesmos, antes de apontar o problema no discurso dos professores da Educação Básica. Para uma tal prática efetiva, chamo a atenção para a importância de ter em vista experiências satisfatórias de educação linguística e de formação de professores (GARCEZ, 2013, p. 217) frente às demandas e contradições da contemporaneidade (HARVEY, 2014), e cuidado com asserções sobre "a escola" - referida assim pelo definido genérico, que negligencia as muitas experiências satisfatórias de educação linguística escolar que certamente vamos encontrar, se procurarmos um pouco.

\section{Formação do professor-autor-formador}

$\mathrm{Na}$ interlocução pedagógica com agentes da Educação Básica, tenho tido a oportunidade, em parceria com colegas formadores de professores (de línguas), de encontrar educadores que praticam educação linguística escolar pautada pelo conceito de letramento conforme discutido aqui. Muitos são professores-autores.

Entendendo que a autoria do professor "implica em construir a própria singularidade nas atividades em que participa e assumir a responsabilidade pela singularidade produzida", (GARCEZ; SCHLATTER, 2017). Margarete Schlatter e eu temos afirmado,

[...] que a autoria se materializa na tomada de posições públicas, expressas na interlocução entre pares e refletidas na prática com os educandos, acerca de princípios e métodos de ensino, e critérios e procedimentos de avaliação [...] [e] se manifesta também, de modo talvez ainda mais evidente, na produção e apreciação compartilhada de materiais e instrumentos de ensino e de avaliação da aprendizagem. (GARCEZ; SCHLATTER, 2017, p. 18)

Assim, temos buscado, primeiro, planejar ações de formação continuada que, igualmente, se pautam pelo conceito de letramento como ponto de referência para a escolha das práticas sociais relevantes para profissionais educadores, e, segundo, executar as atividades de formação coerentemente, isto é, lendo e discutindo textos a fim de fomentar a autoria e logo produzir textos de registro formativo, sejam eles materiais didáticos, planos de atividades pedagógicas ou relatos de prática. Em todos os casos, o convite é para que os educadores se assumam autores. 
"Entendemos que a tarefa do formador universitário é, principalmente, articular o que se observa na prática autoral de professores-autores e promover oportunidades para que eles se encontrem, manifestem suas produções autorais coletivamente e registrem suas experiências" (GARCEZ; SCHLATTER, 2017, p. 21). Ricos repositórios do registro da produção de professores-autores e de professores-autores-formadores ${ }^{10}$ que já atuam na educação linguística escolar e já desenvolvem práticas educativas escolares pautadas pelo conceito de letramento contribuem para fazer avançar os conhecimentos dos colegas educadores, inclusive os nossos, como "especialistas" universitários.

\section{Referências}

ANDERSON, B. Comunidades Imaginadas: Reflexões sobre a origem e a propagação do nacionalismo. Tradução de Denise Bottman. São Paulo: Companhia das Letras, 2008.

ATKINSON, J. M.; HERITAGE, J. Structures of social action. Cambridge: Cambridge University Press, 1984.

BARTON, D.; HAMILTON, M. "Understanding literacy as social practice". In: BARTON, D.; HAMILTON, M. (org.). Local literacies: Reading and writing in one community. Londres: Routledge, 2012 [1998]. p. 3-22.

BRANDT, D.; CLINTON, K. Limits of the local: Expanding perspectives on literacy as a social practice. Journal of Literacy Research, [S.L]. v. 34, n. 3, p. 337-356, 2002.

BRITTO, L. P. L. A sombra do caos: ensino de língua X tradição gramatical. Campinas, SP: Mercado de Letras e ALB, 1997.

BRITTO, L. P. L. O ensino escolar da língua portuguesa como política lingüística: ensino de escrita x ensino da norma. Revista Internacional de Lingüistica Iberoamericana, [S.L]. v. 2, n. 1, p. 119-140, 2004.

BRITTO, L. P. L. Escola, ensino de língua, letramento e conhecimento. Calidoscópio, Vale do Rio dos Sinos, v. 5, p. 24-30, 2007.

DI FANTI, M. G. C. "Gêneros do discurso". In: FLORES, V. N.; BARBISAN, L. B.; FINNATTO, M. J. B.; TEIXEIRA, M. (orgs.). Dicionário de linguística da enunciação. São Paulo: Contexto, 2009. p. 132-133

DURANTI, A. Linguistic anthropology. Cambridge: Cambridge University Press, 1997.

FARACO, C. A. Ensinar x Não ensinar gramática: ainda cabe essa questão? Calidoscópio, Vale do Rio dos Sinos, v. 4, n. 1, p. 15-26, 2006.

FARACO, C. A. Norma culta brasileira: desatando alguns nós. São Paulo: Parábola, 2008.

FARACO, C. A. Linguagem escrita e alfabetização. São Paulo: Contexto, 2012.

\footnotetext{
${ }^{10}$ Em Garcez e Schlatter (2017), tratamos de instâncias de fomento ao registro dessas experiências, como é o caso da Revista Bem Legal ou das iniciativas do Programa Escrevendo o Futuro.
} 
GARCEZ, P. M. "A perspectiva da Análise da Conversa Etnometodológica sobre o uso da linguagem em interação social". In: LODER, L. L.; JUNG, N. M. (orgs.). Fala-em-interação social: uma introdução à Análise da Conversa Etnometodológica. Campinas, SP: Mercado de Letras, 2008. p. 17-38.

GARCEZ, P. M. "Microethnography in the classroom”. In: MAY, S.; KING, K.; LAI, Y.-J. (orgs.). The encyclopedia of language and education. vol. 10, Research methods in language and education. Berlim: Springer, 2017. p. 435-461.

GARCEZ, P. M.; SCHLATTER, M. "Professores-autores-formadores: Princípios e experiências para a formação de profissionais de educação linguística". In: MATEUS, E.; TONELLI, J. R. A. (orgs.). Diálogos (im)pertinentes entre formação de professores $e$ aprendizagem de línguas. São Paulo: Blucher, 2017. p. 13-36. Disponível em: https:/www.blucher.com.br/livro/detalhes/dialogos-im-pertinentes-entre-formacao-deprofessores-e-aprendizagem-de-linguas-1329 . Acesso em: 28 fev.2019.

GARCEZ, P. M.; FRANK, I.; KANITZ, A. Interação social e etnografia: sistematização do conceito de construção conjunta de conhecimento na fala-em-interação de sala de aula. Calidoscópio, Vale do Rio dos Sinos, v. 10, n. 2, p. 211-224, 2012. Disponível em: http://www.unisinos.br/revistas/index.php/calidoscopio/article/view/cld.2012.102.08/986

Acesso em: 28 fev.2019.

GARCÍA, O., \& LIN, A. M. Y. "Translanguaging in bilingual education”. In: GARCÍA, O.; LIN, A. M. Y.; \& S. MAY, S. (orgs.). The encyclopedia of language and education, Vol. 5, Bilingual and multilingual education. Berlim: Springer, 2017. p. 117-130.

GARFINKEL, H., \& SACKS, H. "On formal structures of practical actions". In: MCKINNEY, J. C.; TIRYAKIAN, E. A. (orgs.). Theoretical sociology. New York: Appleton Century Crofts, 1970. p. 337-366.

GIDDENS, A. The constitution of society: Outline of the theory of structuration. Cambridge: Polity Press, 1984.

GIDDENS, A. "Garfinkel, ethnomethodology and hermeneutics". In: GIDDENS, A. Politics, sociology and social theory: encounters with classical and contemporary social thought. Stanford, CA: Stanford University Press, 1995. p. 233-245.

GOFFMAN, E. "A situação negligenciada". In: RIBEIRO, B. T.; GARCEZ, P. M. (orgs.). Sociolinguística Interacional. Tradução de P. M. Garcez. São Paulo: Loyola, 2002. p. 13-20.]

HARVEY, D. Seventeen contradictions and the end of capitalism. Londres: Profile, 2014.

HEATH, S. B. What no bedtime story means: Narrative skills at home and school. Language in Society, [S.L]. v. 11, n. 1, p. 49-76, 1982.

HERITAGE, J. Garfinkel and ethnomethodology. Cambridge: Polity Press, 1984.

IRVINE, J. T.; GAL, S. "Language ideology and linguistic differentiation". In: KROSKRITY, P. V. (org.). Regimes of language: Ideologies, polities, and identities. Santa Fe: School of American Research Press, 2000. p. 35-84. 
JAQUEMET, M. Transidioma. Revista da Anpoll, Florianópolis, v. 40, n. 1, p. 19-32, 2016. Disponível em: http://dx.doi.org/10.18309/anp.v1i40.1012 . Acesso em: 28 fev.2019.

KLEIMAN, A. B. "Modelos de letramento e as práticas de alfabetização na escola". In: KLEIMAN, A. B. Os significados do letramento: uma nova perspectiva sobre a prática social da escrita. Campinas: Mercado de Letras, 1995. p. 15-61.

LILLIS, T.; MCKINNEY, C. The sociolinguistics of writing in a global context: Objects, lenses, consequences. Journal of Sociolinguistics, [S.L]. v. 17, n. 4, p. 415-439, 2013.

LOPES, A. C. et al. Desregulamentando dicotomias: transletramentos, sobrevivências, nascimentos. Trabalhos em Linguística Aplicada, Campinas, v. 56, p. 753-780, 2017.

MOITA LOPES, L. P. "Ideologia linguística: como construir discursivamente o português no século XXI”. In: MOITA LOPES, L. P. (org.). Português no século XXI: ideologias linguísticas. São Paulo: Parábola, 2013. p. 18-52.

SCHLATTER, M. O ensino de leitura em língua estrangeira na escola: uma proposta de letramento. Calidoscópio, Vale do Rio dos Sinos, v. 7, n. 1, p. 11-23, 2009. Disponível em: http://revistas.unisinos.br/index.php/calidoscopio/article/view/4851 . Acesso em: 28 fev.2019.

SCHLATTER, M.; GARCEZ, P. M. Línguas adicionais (Espanhol e Inglês). In: RIO GRANDE DO SUL, Secretaria de Estado da Educação, Departamento Pedagógico, Referenciais curriculares do Estado do Rio Grande do Sul: linguagens, códigos e suas tecnologias. Porto Alegre: SE/DP, 2009. p. 127-172. Disponível em: http://servicos.educacao.rs.gov.br/dados/refer_curric voll.pdf . Acesso em: 28 fev.2019.

SCHLATTER, M.; GARCEZ, P. M. Linguas adicionais na escola: aprendizagens colaborativas em inglês. Erechim, RS: Edelbra, 2012.

SCHLATTER, M.; GARCEZ, P. M. "Portuguese as an additional language: Global trends in local actions". In: CAVALCANTI, M. C.; MAHER, T. M. (orgs.). Multilingual Brazil: Language resources, identities and ideologies in a globalized world. Londres: Routledge, 2017a. p. 267-286.

SCHLATTER, M.; GARCEZ, P. M. Relatos de prática: com a palavra, o professor-autorformador. Na Ponta do Lápis, [S.L] n. 29, p. 12-19, 2017b. Disponível em: https://www.escrevendoofuturo.org.br/arquivos/6528/npl29-jul2017.pdf Acesso em: 28 fev.2019.

SIMÕES, L. J.; MARCHI, D.; FILIPOUSKI, A. M. Língua Portuguesa e Literatura. In: RIO GRANDE DO SUL, Secretaria de Estado da Educação, Departamento Pedagógico, Referenciais curriculares do Estado do Rio Grande do Sul: linguagens, códigos e suas tecnologias. Porto Alegre: SE/DP, 2009. p. 53-123. Disponível em: http://servicos.educacao.rs.gov.br/dados/refer_curric_voll.pdf Acesso em: 28 fev.2019.

SIMÕES, L. J.; RAMOS, J. W.; MARCHI, D.; FILIPOUSKI, A. M. Leitura e autoria: planejamento em língua portuguesa e literatura. Erechim, RS: Edelbra, 2012. 
STREET, B. V. Literacy inequalities in theory and practice: The power to name and define. International Journal of Educational Development, v. 31, n. 6, p. 580-586, 2011.

Pedro de Moraes Garcez pedrom.garcez@ufrgs.br

Recebido em: 10 de Julho de 2019 Aceito em: 20 de Agosto de 2019 Publicado em: Setembro de 2019 